\section{A SELF-CLOSING PLANKTON NET FOR HORIZONTAL TOWING.}

A SELF-CLOSING plankton net has long been needed for horizontal towing. It is especially necessary for the investigation of the vertical distribution of pelagic organisms. Numerous attempts have therefore been made, from the time of Pavesi ( $188_{3}$ ) onward, to devise a satisfactory instrument for this purpose. The latest, and apparently the most satisfactory one of its kind, has been designed by Prof. Kofoid after suggestions from Dr. G. H. Fowler, of the Research expedition.

The net is a ring net with circular opening, which can be both opened and closed under water by messengers. The bag of the net is, as usual, of silk bolting cloth, a simple cone held horizontally by a support. The frame is a heavy casting of phosphor bronze, with enlargements at the horizontal axis for the reception of the hubs of the jaws of the net. The upper end of the frame is expanded to form a head-piece enclosing and protecting the tripping

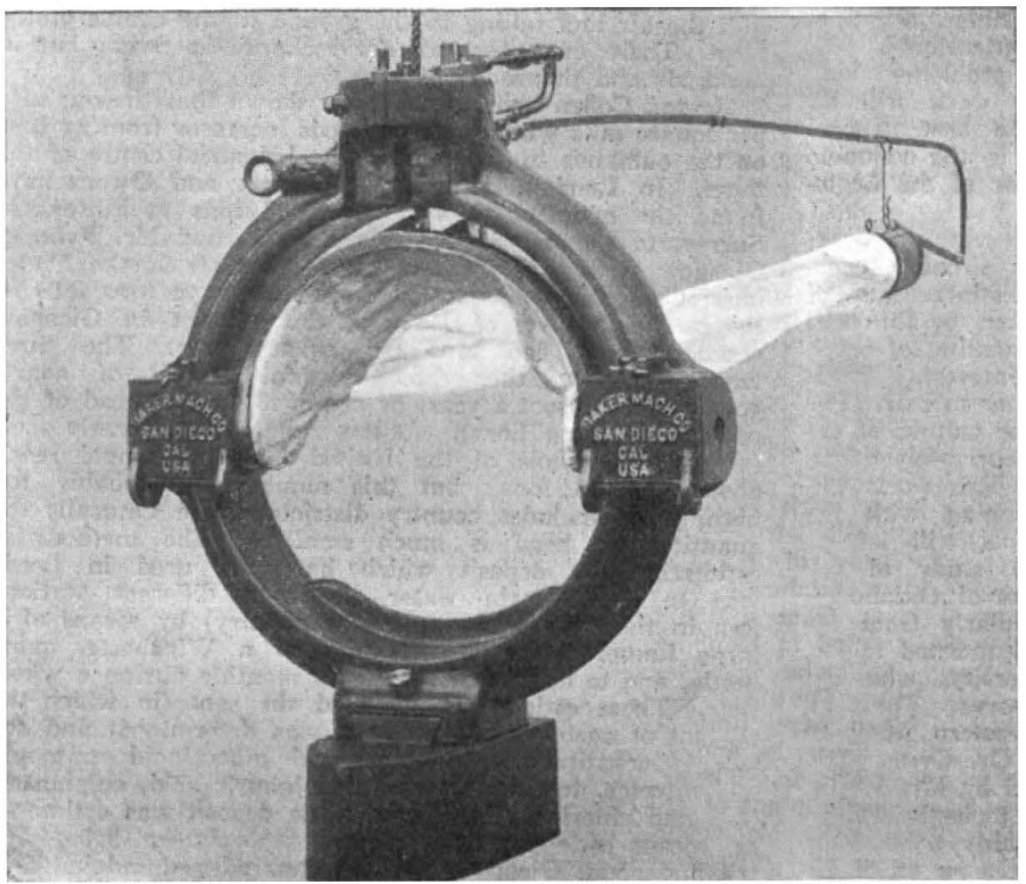

A Self-closing Plankton net.

mechanism for the net jaws, and the lower edge bears a slot for attaching the heavy weights.

The net is balanced in a vertical position by the very heavy lower flatiron-shaped weight.

The mouth of the net is formed not by one continuous ring, but by two hinged jaws, which can both be brought up and held together by the tripping apparatus. In the figure both jaws are in this position, and the net mouth is closed, the net being ready for descending. The two semicircular jaws can rest in three positions: they may be both folded against each other and held upwards as in the figure, or one may be allowed to fall forwards and downwards until both jaws complete a circle and the net mouth is open. In the third position both jaws lie against each other, but hang downwards.

There are two "trips," one of which is operated by the first messenger, the other by the second.

The net is lowered vertically, the ship being at rest, to the desired depth, and the first messenger sent down the cable. This releases the lower jaw, which falls forwards and downwards until the net mouth is open.

After towing is completed and the cable is perpendicular, the second messenger is sent down, and the upper jaw is released. It falls to the lower position, is held firmly against the lower jaw, and thus the net is closed. NO. 2209, VOL. 88]
The advantages which this net possesses over other models are stated by Kofoid to be :-

(I) A method of opening and closing at any level in the sea under complete control of the operator.

(2) Perfect and continuous closure of the net during descent and ascent.

(3) Possibility of horizontal towing.

(4) An opening free from interfering structures which tend to ward off more active pelagic animals.

W. J. D.

\section{THE ANTHROPOLOGICAL SURVEY OF $C A N A D A$.}

THE Dominion of Canada is the first of our colonies to have an official department for the sole purpose of anthropological investigation, and it is to be hoped that this good example will be followed speedily elsewhere. The history of this new departure is briefly as follows.

When the British Association met at Montreal in 1884 , a committee, consisting of Dr. E. B. Tylor, Dr. G. M. Dawson, General Sir J. H. Lefroy, Dr. Daniel Wilson, Mr. Horatio Hale, and others (the personnel of which was subsequently modified), was appointed for the purpose of investigating and publishing reports on the phrsical characters, language, industrial and social condition of the north-western tribes of the Dominion of Canada. The twelfth and final report of the committee was presented at the Bristol meeting in ${ }^{2} \delta g 8$, which, in addition to original articles, contained a summary of the work of the committee in British Columbia by Dr. F. Boas, and an index to reports iv.-xii. In view of the meeting of the association in Toronto in 1897 , a new committee, consisting of several Canadian and British members, was appointed at the Liverpool meeting in 1896 " to organise an ethnologica survey of Canada," of which Dr. George M. Dawson was chairman and secretary. Prof. D. P. Penhallow was elected chairman in I899. The committee suffered a great loss by the death of Dr. Dawson in Igor; he was succeeded by Mr. C. Hill-Tout. Prof. J. L. Myres, in his presidential address to Section $\mathrm{H}$ at Winnipeg, gave a short history of the work of the two committees, and stated that " the premature death of George Dawson in 190 broke the mainspring of the machine: the field-workers fell out of touch with one another and with the subject; the instruments were scattered, and in 1904 the Ethnographic Survey Committee was not recommended for renewal." Thanks mainly to the energy of Prof. J. L. Myres and Mr. E. S. Hartland, a third committee was appointed at Winnipeg, r909, with the Rev. Dr. G. Bryce as chairman and Mr. Hartland as secretary. The Ethnographic Survey Committee reported at the Sheffield meeting in I910 (Report, p. 265) that its work had been crowned with success. The recommendations of this committee at the Winnipeg meeting to the Dominion Government were supported by delegations of the Canadian section of the Archæological Institute of America and the Royal Society of Canada, and on September I, 1910, a division of anthropology under the Geological Survey of Canada was established, of which Dr. E. Sapir was made director. Dr. Sapir is a distinguished student trained by Prof. F. Boas. Dr. Boas is himself intimately acquainted with Canadian ethnology, and in 1888 , under the auspices of the committee of the British Association, began his fieldwork among the north-west tribes which has led to such brilliant results. The inauguration of the new department could not have been put in better hands, but the work was clearly too vast for one man to cover it. On January I, I9I., Mr. C. M. Barbeau, a very promising Canadian 
who had been trained at Oxford, was appointed assistant in anthropology, and on June ${ }_{5}$ Mr. Harlan I. Smith, formerly of the American Museum of Natural History, New York, entered on his duties as archæologist. Mr. Smith is well known as a keen and conscientious archæologist who has done some good work in British Columbia and elsewhere. The Canadian Government deserves hearty commendation for its appreciation of the need of an anthropological survey of Canada, and of the excellent selection of a staff with which to carry it out. May we be permitted to hope that at no distant date the services of a physical anthropologist will be secured?

It is true that a certain amount of work has already been done in Canada; but it has been of a sporadic character, and without any system, except that done by the Jesup North Pacific Expedition; attention should, however, be directed to the series of papers on the Salish tribes published by Mr. Hill-Tout, mainly due to the action of the British Association Committee, and to the fine monograph on "The Great Déné Race," by Father A. G. Morice, in Anthropos, vols. i., ii., iv., v. Dr. Sapir is fully aware of this; and while investigations of limited areas and peoples must first engage the attention of the small staff, he has already mapped out the problems which have to be solved, and thus the detailed work will fill gaps in a well-thought-out scheme. The best general account we have of Canadian ethnology is the valuable Archæological Report, 1905, printed by order of the Legislative Assembly, Toronto, Igo6.

In a report published in Science, December 8, I9II, Dr. Sapir says :- " The ethnological work already undertaken by the division embraces three distinct lines of inquiry. The first of these was undertaken by [himself] among the Nootka, and resulted in the amassing of much material of linguistic and ethnological interest. It is intended to carry forward this work from year to year. The second line of inquiry is the analysis of the culture of the Iroquois, including under this term the Huron-Wyandots, who were never included in the league. This work was undertaken by Mr. Barbeau, who, beginning with the Hurons of Lorette and the few Wyandots still left in western Ontario, took up an intensive study of the most conservative group of Wyandots, those of Oklahoma. The study of the Iroquois proper, particularly from the point of view of social organisation, was entrusted to Dr. A. A. Goldenweiser, of Columbia University, who has amassed much of value at Grand River Reserve. The third point of attack was the culture of the eastern Algonkin tribes. Here a beginning was made by Dr. Cyrus MacMillan, of McGill, among the Micmac, and by Mr. W. H. Mechling among the Malecite. It is hoped to begin systematic work among the Cree, Ojibwa, Plains tribes, and tribes of the Plateau-Mackenzie region as soon as opportunity will permit. So far, the archæological work of the division has been confined to a preliminary reconnaissance, by Mr. Smith, of the field in eastern Canada. Hand-inhand with research and publication, which must naturally form the main activity of an anthropological survey of Canada, is the building up of an anthropological section of the national museum at Ottawa. At present the museum is relatively rich in West Coast ethnological and Ontario archæological material, to the neglect of other fields. Persistent efforts are now being made to round out the resources of the museum.

"The Canadian Government is to be congratulated on having established a systematic survey of aboriginal Canada. Now or never is the time in which to collect from the natives what is still available for study. In some cases a tribe has already practically given up its aboriginal culture, and what can be obtained is merely that which the older men still remember or care to impart. With the increasing material prosperity and industrial development of Canada, the demoralisation or civilisation of the Indians will be going on at an ever-increasing rate. No short-sighted policy of economy should be allowed to interfere with the thorough and rapid prosecution of the anthropological problems of the Dominion. What is lost now will never be recovered again."

This is a very good example of the way in which the overseas meetings of the British Association justify themselves.

NO. 2209, VOL. 88]

\section{SOOT}

THE smoke nuisance, like certain other public abuses, is rapidly approaching the acute phase which seems necessary before the patient town dweller changes his tone from an inarticulate murmur to a muttered complaint sufficiently loud to awaken the slumbering authority to a sense of his duty.

The smoke abatement societies serve as his mouthpiece; they have been formed to collect information, hold conferences, organise exhibitions of smoke-preventing appliances, and generally to create discontent with the present whilst encouraging hope for the future.

These societies have recently banded themselves together into a Smoke Abatement League, one of the objects of which is to persuade the Local Government Board to modify the present method of dealing with smoky chimneys. If statistics furnish any guide for public action, the League has fully justified its aims. Within the last few months facts have been forthcoming from different and quite independent sources showing not only the nature of soot and its effects, but the actual amounts discharged into the air and falling to the ground in the course of the year. These quantities are not reckoned in cwts., but in hundreds and thousands of tons.

Messrs. Cohen and Ruston have shown that the quantity per square mile which falls in Leeds increases from 25 tons on the outskirts to 539 tons in the industrial centre of the town. In London, Messrs. Des Vœux and Owens have found the quantity to vary from $5^{8}$ tons at Sutton, in Surrey, to 426 tons in Old Street, E.C., and Mr. Fyfe, of Glasgow, in a paper read at the Manchester Smoke Abatement Conference, has found that whereas 72 tons falls at the seaside village of Bo'ness, the amount in Glasgow reaches about 820 tons per square mile. The three large towns together show a total deposit of nearly 50,000 tons of soot a year, or about $18 \mathrm{lb}$. per head of the population ( $6 \frac{1}{4}$ millions). At the same rate the yearly sootfall for the whole of the United Kingdom would reach about 300,000 tons; but this number is probably too high, as it includes country districts where naturally the quantity per head is much smaller. The method for estimating the deposit which has been used in Leeds was to collect rain water at eleven different stations (ten in the town and one in the country) by means of a large funnel placed in the neck of a Winchester quart bottle, and to analyse the contents monthly during a whole year. These estimations included the soot (in which the content of carbon, tar, and ash was determined) and the soluble constituents, viz. free and albuminoid ammonia and nitrates, free and combined sulphuric acid, sulphurous acid and chlorine. In Glasgow the deposit was estimated by means of eighty-three dust boxes, sixteen being distributed about Glasgow and the remainder placed in other districts. They were left for two months (December, I9Io, and January, I9II), and the contents were then weighed and analysed for carbon, tar, and ash. Messrs. des Vœux and Owens have used a similar method to that adopted in Leeds, but on a much larger scale, substituting for the funnel a large hopper connected with a capacious bottle. The contents were treated as in Leeds, both insoluble and soluble constituents being estimated. The experiments were also continued throughout the year. There does not seem to be any great advantage gained by the substitution of the larger and more costly apparatus for the funnel and Winchester quart bottle if the analyses are carried out with sufficient care.

In addition to the monthly sootfall, the Leeds experiments have included the estimation of the total soot discharged from domestic and factory chimneys, and the still more important permanent deposit of tar, which is the prime agent in the discoloration of buildings and foliage, and (on account of its acid character) in the destruction of masonry, mortar, fabrics, and vegetation. The quantity of soot produced in Leeds annually from factory and domestic chimneys is roughly 35,000 tons, which is distributed as follows :-

" "Sont: its Character and Composition." By Cohen and Ruston. ( Tourn. Soc. Chem. Ind., December 15,1911 .)

"Air Pollution in Glasgow and Other Towr.s in Scotland." By Pe:er Fyfe. Paper read at the Manchester Smoke Abatement Conference, November, rori.

"The Sootfall of London." (The Lancet, January 6, x9ז2.) 